\title{
A sintomatologia depressiva entre lésbicas, gays, bissexuais e transexuais: um olhar para a saúde mental
}

\author{
Symptoms of depression among lesbians, gays, bisexuals, and transsexuals: a look at mental health \\ La sintomatología depresiva entre lesbianas, gays, bisexuales y transexuales: una mirada hacia la salud mental
}

Dayana Souza de Melo'; Bianca Luna da Silva"'; Rosâne Mello"l'

\begin{abstract}
RESUMO
Objetivo: analisar a incidência da sintomatologia depressiva entre lésbicas, gays, bissexuais e transexuais (LGBT), de dois cenários distintos, e sua relação com a sexualidade desses indivíduos. Método: pesquisa quantitativa, mediante análise estatística, realizada entre os anos de 2016 a 2018, e que aplicou o Inventário de Depressão de Beck - II (BDI- II) do Hospital Uiversitário Gaffrée e Guinle (HUGG) e na Escola de Enfermagem Alfredo Pinto (EEAP), ambos localizados no município do Rio de Janeiro. Participaram 76 pessoas. A pesquisa foi aprovada por Comitê de Ética. Resultados: No HUGG foi observado indicativo de depressão mínima. Na EEAP, foi observado indicativo de depressão moderada. As disparidades podem ser justificadas pela diferença de idade, os impactos do processo de disclosure e estigmas do portador de HIV. Conclusão: observouse que a família é fundamental na saúde mental entre LGBT e que é necessário mais pesquisas sobre o tema. Descritores: Sexualidade; minorias sexuais e de gênero; depressão; saúde mental.
\end{abstract}

\begin{abstract}
Objective: to examine the incidence of symptoms of depression among lesbian, gay, bisexual, and transgender (LGBT) people from two different scenarios, and their relationship with these individuals' sexuality. Method: this quantitative study, using statistical analysis was conducted between 2016 and 2018 by applying the Beck Depression Inventory - II (BDI-II) to 76 participants at the Gaffrée e Guinle University Hospital and the Alfredo Pinto School of Nursing, both in Rio de Janeiro city. The study was approved by the research ethics committee. Results: indications of minimal depression were found at the hospital, while at the school of nursing, indications of moderate depression were observed. These disparities may be explained by the age difference, the impacts of the disclosure process, and stigmas attached to people with HIV. Conclusion: the family was found to be fundamental in mental health among LGBT people, and further research on the subject is needed.

Descriptors: Sexuality; sexual and gender minorities; depression; mental health.

\section{RESUMEN}

Objetivo: analizar la incidencia de sintomatología depresiva entre lesbianas, gays, bisexuales y transexuales (LGBT), en dos escenarios distintos, y la relación de esos individuos con su sexualidad. Método: investigación cuantitativa por medio de un análisis estadístico, realizada entre 2016 y 2018, con la aplicación del Inventario de Depresión de Beck-II (BDI-II) del Hospital Universitario Gaffrée e Guinle (HUGG) y en la Escuela de Enfermería Alfredo Pinto (EEAP), ambos ubicados en la ciudad de Río de Janeiro. Participaron 76 personas en total. La investigación fue aprobada por el Comité de Ética. Resultados: En el HUGG, se observó un indicativo de depresión mínima. En la EEAP, se observó un indicativo de depresión moderada. Las disparidades pueden estar justificadas por las diferencias de edad, los impactos del proceso de divulgación y los estigmas del portador del VIH. Conclusión: Se observó que la familia es fundamental para la salud mental LGBT y que hace falta más investigación sobre dicho tema.
\end{abstract}

Descriptores: Sexualidad; minorías sexuales y de género; depresíon; salud mental.

\section{INTRODUÇÃO}

A depressão é uma doença cada vez mais presente na sociedade contemporânea. No ano de 2017, a Organização Mundial da Saúde (OMS) afirmou que mais de 300 milhões de pessoas vivem com depressão, além de apontar um aumento de $18 \%$ entre os anos de 2005 e $2015^{1}$.

Devido ao estilo de vida na contemporaneidade, guiado pelo capitalismo e a busca de crescimento pessoal regido pelo princípio de meritocracia, a população está sujeita a maior carga de estresse advinda de uma rotina cada vez mais acelerada, o que diminui os momentos de relaxamento e autocuidado dos indivíduos. Dessa forma, a vulnerabilidade às desordens mentais aumenta, entre elas a depressão e aparecimento de seus sintomas ${ }^{2}$.

A depressão é um transtorno mental comum, que tem entre suas principais características tristeza persistente, presença de humor depressivo e redução da capacidade de experimentar prazer em atividades antes consideradas agradáveis. Desânimo ou sensação de perda de energia, retraimento social e apatia também são sintomas comuns, com possibilidade de evolução para pensamentos e até tentativas de autolesão e suicídio ${ }^{3}$.

'Graduanda em enfermagem pela Universidade Federal do Estado do Rio de Janeiro. Rio de Janeiro, Brasil. E-mail: dayanasouza_10@hotmail.com

"Enfermeira. Residente do programa multiprofissional em saúde mental pela Universidade Estadual do Rio de Janeiro. Rio de Janeiro, Brasil. E-mail: luna13.bianca@gmail.com '"Enfermeira. Doutora. Professora Adjunta. Universidade Federal do Estado do Rio de Janeiro. Rio de Janeiro, Brasil. E-mail: rosane.dv@gmail.com 
Suas causas são divididas em três categorias: biológica, genética e psicossocial. Os fatores biológicos são sustentados por alterações químicas no cérebro do indivíduo acometido, mais especificamente os neurotransmissores e receptores ${ }^{4}$. Quanto ao fator genético, existem estudos psiquiátricos que evidenciam maior frequência deste distúrbio em certas famílias ${ }^{5}$ e que o risco para familiares de primeiro grau de portadores do quadro é de duas a três vezes maior ${ }^{6}$. Já os fatores psicossociais estão relacionados ao modo como a pessoa percebe e interpreta os acontecimentos da vida, como lida com seus próprios sentimentos e principalmente com o estresse das pressões sociais ${ }^{4}$.

Aliado a isto, temos o enfoque na população de lésbicas, gays, bissexuais e transexuais (LGBT), que, por terem comportamentos que diferem da convenção social da maioria, ou seja, da heteronormatividade, é atingida por demonstrações públicas de preconceito, agressões físicas, verbais e/ou psicológicas, têm seus direitos violados, entre outros. Destarte, o Relatório Violência LGBTFóbicas no Brasil e o Relatório de Violência Homofóbica no Brasil, iniciativa do Governo Federal, lançou dados oficiais sistematizados no país. Em 2012 foram reportadas 3.031 denúncias através do Disque Direitos Humanos (Disque 100), em 2013 as violências nesta população geraram 1.906 vítimas; por fim, foram contabilizadas 21.060 violações entre os anos de 2011 a $2016^{7,8}$.

O Brasil apresenta um dos maiores índices do mundo de violência contra a população LGBT, e estes casos são, muitas vezes, tratados com descaso e impunidade ${ }^{9}$. Tal cenário gera sofrimento psicossocial intenso, decorrente de uma atmosfera social ansiogênica, que muitas vezes resulta em conflitos internos, angústia e insegurança, deixando a população LGBT mais propensa a manifestar sintomas depressivos ${ }^{10}$.

Assim, a presente pesquisa objetivou analisar a incidência da sintomatologia depressiva entre indivíduos LGBT de dois cenários distintos, e sua relação com a sexualidade dos participantes.

\section{REVISÃO DE LITERATURA}

O estudo se baseou na Política Nacional de Saúde Integral de Lésbicas, Gays, Bissexuais, Travestis e Transexuais (Política Nacional de Saúde Integral LGBT), no âmbito do Sistema Único de Saúde (SUS). O título foi escolhido por ser marco de um avanço significativo nacional e um dos principais documentos do governo brasileiro que atende a esta população ${ }^{11}$. Ressalta-se o que é referido na seção de Objetivos Específicos desta Política, no item XX, que intenta "reduzir os problemas relacionados à saúde mental, drogadição, alcoolismo, depressão e suicídio entre lésbicas, gays, bissexuais, travestis e transexuais, atuando na prevenção, promoção e ....recuperação da saúde" ${ }^{12: 21}$, uma vez que os dados obtidos poderão contribuir para o direcionamento de ações voltadas a esta população.

Entende-se que a origem do preconceito contra os LGBTs no Brasil está relacionada com as bases morais e religiosas sobre as quais o país se formou. Esta estrutura, mantida até os dias atuais, reflete nesta população sob a forma de opressão, frustração, vergonha de si mesmo, baixa autoestima, entre outros, levando ao processo de adoecimento dessas pessoas ${ }^{9}$.

Embora existam desdobramentos constitucionais destinados à garantia da saúde e seu acesso à população LGBT, o estigma social não pode ser ignorado, principalmente nas suas relações sociais, como família e serviços de saúde ${ }^{13}$. Quanto ao último, existe uma resistência desses usuários de acessarem tais dispositivos, uma vez que se sentem inseguros e receosos de expressarem sua sexualidade, devido ao medo social e ao despreparo dos profissionais para lidar com as questões específicas inerentes a este grupo. Vale enfatizar que o tema ainda é escassamente tratado na formação dos trabalhadores de saúde, que também são atravessados pela heteronormatividade cultural e historicamente ${ }^{14}$. Por isso, o desafio encontra-se em modificar este panorama, para que os conceitos de universalidade, integralidade e equidade sejam abarcados.

Faz-se importante definir alguns termos, como sexo e gênero. O sexo é definido no nascimento, por fatores orgânicos, como órgão sexual, por exemplo. O gênero é uma característica socialmente adquirida a partir de comportamentos e aspectos culturalmente atribuídos a cada sexo biológico, tratando-se assim, de uma classificação pessoal de identidade. Essa identificação pode ou não ser concordante com a expressão atribuída ao seu gênero de nascimento, que é baseada no sexo. Quando a díade sexo-gênero é concordante, chamamos o indivíduo de cisgênero; quando difere, temos o termo transgênero. $O$ transexual é um termo genérico atribuído aos transgêneros ${ }^{15}$.

É importante lembrar que esses papéis não são apenas um processo biológico, sendo também fruto do meio sociocultural, e que, no caso do nosso modo de sociedade heteronormativa, qualquer disparidade que não esteja dentro do padrão dual e moralmente aceito de "homem" e "mulher" é vista como condição anormal e, até mesmo, patológica ${ }^{14}$

A orientação sexual, por outro lado, se refere à atração sexual-afetiva de um indivíduo. Ela é regida pelo gênero, e não pelo sexo. Desta forma, quando ela ocorre pelo gênero oposto, é classificado como heterossexual; quando pelo mesmo, homossexual; quando por ambos, bissexual. Temos ainda o termo assexual para pessoas que não sentem atração por nenhum dos gêneros ${ }^{15}$. 


\section{MEtodologia}

O presente estudo é uma pesquisa quantitativa, de caráter descritivo e exploratório. A pesquisa ocorreu entre setembro de 2016 a setembro de 2018 e em dois cenários: um Ambulatório de Imunologia do Hospital Universitário Gaffrée e Guinle, localizado no município do Rio de Janeiro (Cenário I), e na Escola de Enfermagem Alfredo Pinto (Cenário II). Tal escolha se deu por termos de conveniência e proximidade nos mesmos, e pela observação empírica da presença da população alvo do estudo em ambos os locais.

Como critério de inclusão, foi estabelecido que os participantes fossem maiores de 18 anos e que se identificassem como integrantes da população LGBT. Tal correspondência era dada na apresentação da pesquisa aos candidatos, onde explicou-se os objetivos e propôs-se a participação. Como critério de exclusão, estabeleceu-se que seria o indivíduo que se autodeclarassem cisgênero de orientação heterossexual exclusiva.

Ao todo, foram entrevistados 78 sujeitos: 14 provenientes do Cenário I, e 46 do Cenário II. Neste último, contudo, dois não foram contabilizados, pois ambos se autodenominaram cisgênero de orientação heterossexual exclusiva.

Primeiro, com o convite de participação, o estudo foi apresentado junto com ao Termo de Consentimento Livre e Esclarecido, elucidando os candidatos quanto ao estudo e o seu papel nele. Aos que aceitaram, foram entregues instrumentos com suas respectivas orientações de preenchimento.

O primeiro foi o Inventário de Contextualização do Sujeito (ICS), que foi aplicado com o objetivo de obter informações básicas para a análise, como a orientação sexual do indivíduo. Foi utilizada a Escala de Kinsey, uma tabela com sete níveis, criada para classificar a orientação sexual humana de forma mais específica e flexível. Os níveis são: heterossexual exclusivo; heterossexual, com relações homossexuais isoladas; heterossexual, com relações homossexuais frequentes; bissexual; homossexual, com relações heterossexuais isoladas; homossexual, com relações heterossexuais frequentes; homossexual exclusivo ${ }^{16}$.

O segundo instrumento foi a versão traduzida para o português do Inventário de Depressão de Beck -II (BDI- II), para identificação de sintomas de depressão. O BDI-II consiste num questionário de 21 itens, com diferentes alternativas, que correspondem às classificações, dadas em ordem crescente de gravidade. As questões possuem respostas que variam de 0 a 3. Somando-se os valores das opções escolhidas, é possível obter o somatório, que é classificado em: mínimo (de 0 a 13 pontos), leve (de 14 a 19 pontos), moderado (de 20 a 28 pontos) e grave (de 29 a 63 pontos) ${ }^{17}$.

A análise dos dados se deu pela quantificação encontrada no BDI-II, relacionadas ao perfil dos entrevistados, colhido a partir do ICS. Para o tratamento desses elementos, aplicou-se a análise estatística, com cálculos de frequência absoluta e percentual e de medidas de tendência central.

Foram adotados números para a identificação dos entrevistados, por ordem de participação, separados por cenários, de forma tal que suas identidades não fossem expostas.

O projeto foi submetido ao Comitê de Ética em Pesquisa da Universidade Federal do Estado do Rio de Janeiro e aprovado sob o Parecer de número 1.672.502, de acordo com a Resolução n 466/2012, do Conselho Nacional de Saúde, que regula a pesquisa envolvendo seres. O sigilo quanto à identificação dos participantes da pesquisa foi mantido em todas as fases do estudo.

\section{RESULTADOS E DISCUSSÃO}

Obtiveram-se 78 participantes do estudo no total, dos quais 14 pertenciam ao Cenário l e 64 ao Cenário II. Porém, apenas 76 foram contabilizados, haja vista que dois corresponderam ao critério de exclusão.

\section{Cenário I}

Dos 14 participantes, foi obtida totalidade de indivíduos cisgêneros. A faixa etária variou entre 28 e 52 anos, tendo uma média de idade de 39 anos; mediana de 40,5 anos e moda de 30 anos.

Devido à característica deste cenário, $12(85,7 \%)$ entrevistados eram portadores do Vírus da Imunodeficiência Humana (HIV).

No que concerne à orientação sexual ${ }^{16}$ a maioria, $10(71,4 \%)$, entende-se como homossexual exclusivo, como disposto na tabela 1.

Quando questionados sobre sentimento de discriminação/desrespeito em relação à própria orientação sexual/expressão de gênero, foram apresentadas cinco opções: sempre; frequentemente; de vez em quando; raramente; nunca. A tal pergunta, apenas $4(28,6 \%)$ da amostra relatou "nunca" experimentar a sensação. Todavia, o sentimento ainda se faz presente em número considerável, $10(71,4 \%)$. O resultado é pertinente, uma vez que a exposição em longo prazo ao sentimento discriminatório e desrespeitoso foi identificado como maior contribuinte para a disparidade na prevalência de prejuízos na saúde mental da população LGBT, quando comparada aos indivíduos inseridos na heteronormatividade ${ }^{15}$. 
TABELA 1: Distribuição de pessoas LGBT do cenário I por orientação sexual. Rio de Janeiro - Brasil, 2018. $(n=14)$

\begin{tabular}{ll}
\hline Orientação Sexual & $\mathbf{f ( \% )}$ \\
\hline Heterossexual Exclusivo & - \\
Heterossexual, com relações homossexuais isoladas & - \\
Heterossexual, com relações homossexuais frequentes & $2(14,2)$ \\
Bissexual & $1(7,1)$ \\
Homossexual, com relações heterossexuais isoladas & - \\
Homossexual, com relações heterossexuais frequentes & $1(7,1)$ \\
Homossexual Exclusivo & $10(71,4)$ \\
\hline
\end{tabular}

Quanto ao sentimento de tristeza em razão de situações vividas relacionadas à orientação sexual/expressão de gênero, 13(92,9\%) responderam que não a sentem.

Vale ressaltar que o único participante que respondeu afirmativamente neste quesito, justificava sua tristeza advinda do preconceito experimentado no cotidiano, não por sua orientação sexual e/ou expressão de gênero, mas sim por ser portador do HIV e, por isso, sofrer o estigma.

Esse agravo ainda hoje é marcado pelo preconceito atrelado à população LGBT em associação com faces negativas como mortalidade e medo. Esta correlação HIV e LGBT é histórica, pois, desde o início da pandemia da Síndrome da Imunodeficiência Humana (AIDS), na década de 1980, houve um expressivo número de casos neste grupo ${ }^{18}$.

Nos resultados obtidos no segundo instrumento, o BDI - II, tivemos uma média de pontuação de 11,2 (Mínimo), mediana de 11,5 (Mínimo) e moda de 10 (Mínimo).

Apesar de homens gays e bissexuais apresentarem probabilidade duas vezes maior em serem diagnosticados com depressão quando comparados com homens heterossexuais ${ }^{15}$, os dados mostraram pontuações com predominância de sintomatologia depressiva mínima e leve 13(92,9\%), e 1(7,1\%) moderada. Tais números são coerentes àqueles expostos na questão sobre sentimento de tristeza em razão de situações vividas relacionadas à orientação sexual/expressão de gênero, onde apenas $1(7,1 \%)$ dos entrevistados relata o sentimento e, mesmo assim, o incômodo maior parte de um estigma da doença sobressaindo-se à sua sexualidade. Como exemplo disso, podemos citar figuras públicas que vivenciaram o HIV e que foram estigmatizadas e rotuladas por sua associação com a não heteronormatividade, como os cantores e compositores Cazuza e Freddie Mercury ${ }^{18}$.

Ademais, os valores são justificáveis se analisados conjuntamente com o fato de que $12(85,7 \%)$ desses entrevistados são portadores de HIV, o que vai ao encontro ao exposto pela Teoria da Autotranscedência de Reed. Nesta Teoria, Reed afirma que a autotranscedência é uma capacidade de desenvolvimento que se torna evidente em situações que confrontem a pessoa com sua mortalidade pessoal, através de experiências de saúde como envelhecimento, doença e perda, facilitando o bem-estar em momentos em que uma pessoa experimenta vulnerabilidade ou está tentando superar uma dificuldade ${ }^{19}$.

\section{Cenário II}

Dos 62 participantes contabilizados, foram identificados $60(96,8 \%)$ cisgêneros e $2(3,2 \%)$ transgêneros. A faixa etária variou entre 19 e 50 anos, tendo uma média de idade equivalente a 23,6 anos; mediana de 23 anos e moda de 22 anos. Percebe-se aqui, uma população majoritariamente composta por jovens adultos.

Desta amostra, apenas $11(17,7 \%)$ relataram possuir algum tipo de doença crônica, como hipertensão arterial sistêmica e lúpus, por exemplo.

Relativo à orientação sexual ${ }^{16}$, a maioria, $28(45,1 \%)$ entendem-se como bissexual, seguido por homossexual exclusivo: $15(24,1 \%)$ dos entrevistados, de acordo com a tabela 2.

Sobre o sentimento de discriminação/desrespeito em relação à própria orientação sexual/expressão de gênero, 59(95,2\%) referiram o sentimento em maior ou menor escala. Tal número se mostra alarmante, uma vez que a exposição frequente a discriminação, desrespeito e agressões de diversas formas e níveis são fatores que interferem negativamente na saúde mental desses indivíduos, aumentando os riscos de aparecimento de sintomas ansiosos, depressivos, abuso de substâncias, autolesão e suicídio ${ }^{20}$. 
TABELA 2: Distribuição de pessoas LGBT do cenário II por orientação sexual. Rio de Janeiro- Brasil, 2018. (n=62)

\begin{tabular}{ll}
\hline Orientação Sexual & $\mathbf{f}(\mathbf{\%})$ \\
\hline Heterossexual Exclusivo & $1(1,6)$ \\
Heterossexual, com relações homossexuais isoladas & $2(3,2)$ \\
Heterossexual, com relações homossexuais frequentes & $1(1,6)$ \\
Bissexual & $28(45,1)$ \\
Homossexual, com relações heterossexuais isoladas & $14(22,5)$ \\
Homossexual, com relações heterossexuais frequentes & $1(1,6)$ \\
Homossexual Exclusivo & $15(24,1)$ \\
\hline
\end{tabular}

Quanto à tristeza em decorrência de situações vividas relacionadas com a orientação/expressão de gênero, confirmou-se que $39(62,9 \%)$ pessoas a referem, seja pela discriminação sofrida ou por uma sensação de não aceitação da sociedade. Os valores morais de uma sociedade inferem no direito à liberdade de expressão do indivíduo. Na atual conjuntura, o "estresse das minorias", expressão que define o principal fator de estresse de determinado grupo minoritário social, é pautado principalmente em esconder sua sexualidade e gênero. Esse fator estressante advém, por exemplo, do medo de manifestações violentas de LGBTfobia ${ }^{9}$.

No questionário aplicado, dos que responderam afirmativamente, 23(59\%) relacionaram a tristeza com questões familiares, por não se sentirem seguros para expressar sua sexualidade, devido ao medo de represálias. Muitas vezes, tal situação se manifesta por uma opressão implícita neste ambiente, ilustrada por discursos homofóbicos e religiosos, atravessados pela relação de poder da família sobre o sujeito, ainda dependente de seu "suporte".

O desenvolvimento da saúde biopsicossocial do jovem dentro da dinâmica familiar, é inferida por cada um dos membros; em situações onde este indivíduo se percebe excluído por não atender a padrões socialmente estabelecidos, os vínculos entre eles ficam fragilizados, sendo fator de risco para agravos multiaxiais ${ }^{13}$. A rejeição familiar tem se mostrado como fator agravante à depressão e tentativas de suicídio. Em contrapartida, o suporte é visto como protetor a estes fatores, mais do que o apoio de companheiros de causa ou outras pessoas importantes ${ }^{21}$.

Corroborando este fato, há os resultados obtidos na pontuação do BDI-II, com média de 22,5 (Moderado), mediana de 22 (Moderado) e moda de 30 (Grave). Identificou-se que 22(35,4\%) entrevistados apresentaram a sintomatologia grave, sendo este o nível com maior incidência, como disposto na tabela 3.

TABELA 3: Distribuição de pessoas LGBT do cenário II, de acordo com classificação do BDI- II, Rio de Janeiro- Brasil, 2018. ( $n=62)$

\begin{tabular}{lc}
\hline CLASSIFICAÇÃO NO BDI-II & $\mathbf{f}(\%)$ \\
\hline Mínimo & $14(22,5)$ \\
Leve & $13(20,9)$ \\
Moderado & $13(20,9)$ \\
Grave & $22(35,4)$ \\
\hline
\end{tabular}

Evidenciada a importância da família para a saúde mental de jovens integrantes da população LGBT, fica explicado o impacto observado na saúde mental deste grupo, onde dos $23(59 \%)$ participantes que justificaram a família como fonte da tristeza, mais da metade - 12(52,2\%) - apresenta classificação "grave".

Os dados são preocupantes, pois dos 35(56,4\%) participantes classificados como moderado e grave, 23(65,7\%) relatam também não procurar um serviço de saúde para apoio nestas questões. Neste contexto, o SUS reconhece as especificidades de demanda deste grupo, porém compreende os desafios de formular medidas de acesso universal pautado na equidade ${ }^{14}$, o que pode vir a interferir na falta de suporte de saúde relatado pelos entrevistados. 


\section{Disparidades entre os cenários}

Nota-se que entre os cenários estudados, os dados diferem em alguns aspectos. Ao passo que no Cenário I o sentimento de tristeza em relação à orientação sexual/expressão de gênero foi exposto por apenas $1(7,1 \%)$ dos entrevistados, no Cenário II este panorama se inverte, apresentando uma maioria de 36(62,9\%) dos 62 entrevistados neste eixo. À semelhança disto, seguem-se sobre a frequência do sentimento de discriminação/desrespeito, onde no Cenário I 9(64,3\%) entrevistados responderam "nunca" e "raramente", contra apenas 16(25,8\%) das mesmas respostas no Cenário II.

Como já citado, a exposição em longo prazo a sentimentos de discriminação/desrespeito aumenta os riscos de prejuízos na saúde mental ${ }^{15}$. Desta forma, podemos observar aqui um risco mais elevado para os participantes do Cenário II, por maior prevalência de relatos destes sentimentos.

Há ainda as pontuações obtidas no BDI-II. O Cenário I apresentou resultados mais amenos (média classificada como "mínima") quando comparado ao Cenário II (média classificada como Moderada).

Ainda neste aspecto, outra disparidade a ser considerada é a idade de cada grupo. Enquanto no Cenário I a amostra consistiu em uma população mais madura, com uma média equivalente a 39,2 anos, no Cenário II temos a predominância de jovens em torno dos 20 anos. Pensando que jovens adultos podem encontrar estressores relacionados no que concerne a firmar sua identidade, construir uma carreira profissional e obter independência, estes mesmos jovens quando são parte integrante de uma minoria encontram uma carga maior de estresse ${ }^{22}$. Isto pode ser traduzido como mais um sinal de alarme no que tange a saúde mental destes indivíduos, uma vez que variáveis como demonstrações de preconceito, falta de suporte social e apoio familiar, e vitimização são fatores associados a problemas de saúde mental na população LGBT ${ }^{23}$.

Ademais, é possível também fazer a relação com o processo de disclosure, termo que significa o momento de revelação e manifestação da própria sexualidade perante a sociedade ${ }^{24}$. Mesmo que este processo possa expor uma pessoa à hostilidade e preconceito de outras, ele representa uma relação positiva do indivíduo com si mesmo, e isto tem sido associado a resultados positivos na saúde ${ }^{21}$.

Ressalta-se também que o disclosure fortalece os laços dentro do grupo LGBT, que usualmente se sentem mais à vontade em se expressar diante daqueles com quem compartilham as mesmas particularidades ${ }^{24}$, firmando sua identidade, o que tem relação direta com a sensação de fazer parte de um grupo. Isto faz com que se formem laços de suporte mútuo, conexões sociais e um senso de pertencimento, o que alivia os efeitos negativos do estresse sofrido devido à discriminação 22 .

Tal afirmativa é relevante visto que um suporte social precário, com desconexão e baixo senso de pertencimento à comunidade leva à solidão e são relacionados com prejuízos na saúde física e mental deste grupo ${ }^{25}$.

Para maior clareza nas justificativas das diferenças observadas, voltemos para o Cenário I. Trata-se de um grupo mais maduro, que apresenta apenas $5(35,7 \%)$ que ainda residem com pais/parentes, indicando uma população que já alcançou certos níveis de independência e superou os diversos estressores da juventude. Isto vai ao encontro do exposto pela Teoria da Autotrascedência de Reed. Ela afirma que a autotranscedência é uma capacidade de desenvolvimento que se torna evidente em experiências limite/extremas, retratando uma mudança que ocorre na pessoa e no contexto que a envolve ${ }^{26}$. O HIV - presente em $12(85,7 \%)$ da amostra - somado ao estigma desta condição ${ }^{27}$, quando relacionadas com as pontuações mais amenas obtidas no BDI-II, nos indica a influência da tríade vulnerabilidade, autotranscedência e bem-estar, fundamentada por Reed.

\section{CONCLUSÃO}

A população LGBT apresenta vulnerabilidade relativa às questões de saúde mental. A frequente exposição a discriminação e ao desrespeito adicionada a expectativa de rejeição e necessidade de dissimulação de sua identidade impacta negativamente na saúde mental destes indivíduos. Resultados disto foram expostos principalmente no Cenário II, onde a média obtida entre os participantes foi classificada como moderada, de acordo com o BDI-II.

Todavia, disparidades foram encontradas entre os grupos. Elas podem ser justificadas pela diferença de idade dos participantes dos dois cenários, onde o Cenário I apresenta uma população mais madura e independente em comparação ao segundo. Esta inferência é defendida pelo exposto na Teoria de Autotranscedência de Reed, quando considerado que os participantes do Cenário I já passaram por experiências estressoras próprias da juventude. Além disso, o fato de sua maioria ser portadores do HIV, um agravo crônico e ainda sem cura, colabora com a teoria supracitada. Aliás, tal frequência e a ausência de números maiores para análise é resultado do cenário disponível, apontando uma limitação do estudo. 
A família se mostra como fator decisivo, uma vez que a maioria estudada no Cenário II reside com pais/parentes. A relevância da família é expressiva também aparecendo nas justificativas de tristeza vivenciada por mais da metade dos participantes. Destes, houve predominância de classificação grave no BDI-II.

Ademais, o processo de disclosure representa uma relação positiva da pessoa com sua própria sexualidade, e isto tem sido associado a resultados positivos na saúde mental. Assumir sua identidade fortalece os laços dentro da própria comunidade LGBT, que usualmente sentem-se mais à vontade em se expressar diante daqueles com quem compartilham tais particularidades.

Por fim, a realização desta pesquisa evidenciou a necessidade de mais estudos voltados para a saúde mental da população LGBT, suas relações com a família e com a sociedade, de modo a elucidar a dimensão do impacto negativo que a não aceitação das diferenças têm sobre estes indivíduos e, desta forma, realçar as formas de combatê-la.

\section{REFERÊNCIAS}

1. PAHO- Organização pan-americana de saúde. Com depressão no topo da lista de causas de problemas de saúde, OMS lança a campanha "Vamos conversar"; [Internet] 2017 [cited 2018 Jan 10]; Available from:

https://www.paho.org/bra/index.php?option=com_content\&view=article\&id=5385:com-depressao-no-topo-da-lista-decausas-de-problemas-de-saude-oms-lanca-a-campanha-vamos-conversar\&ltemid=839.

2. Mendes ED, Viana TDC, Bara O. Melancholy and depression: a psychoanalytic study. Psicologia: Teoria e Pesquisa. 2014 [cited 2018 Jan 10]; 30(4):423-31. Available from: http://www.scielo.br/scielo.php?script=sci_arttext\&pid=S010237722014000400007

3. Association AP, Manual diagnóstico e estatístico de transtornos mentais: DSM-5. 5a edição. Porto Alegre (RS): Artmed; 2014.

4. Anibal C, Romano LH. Relation between physical activity and depression: review study. Revista Saúde em Foco. 2017 [cited 2018 Jan 10]; 9:190-99. Available from: http://portal.unisepe.com.br/unifia/wpcontent/uploads/sites/10001/2018/06/021_artigo_cintia.pdf.

5. Oliveira LA, Oliveira VC. Os transtornos depressivos: um olhar sobre a reestruturação dos cuidados em saúde mental Rev. Psicol. Saúde e Debate. 2018 [cited 2018 Jan 10]; 4(3):96-109. DOI: http://dx.doi.org/10.22289/2446-922X.V4N3A9.

6. Jacondino CB, Borges CA, Gottlleb MG. Association of oxytocin receptor gene polymorphisms rs53576 and rs2254298 with depression: a systematic review. Scientia Medica. 2014 [cited 2018 Jan 10]; 24(4):411-19. DOI: http://dx.doi.org/10.15448/1980-6108.2014.4.18173.

7. Secretaria de Direitos Humanos (Br). Violência LGBTfóbicas no Brasil: dados da violência. 2018 [cited 2018 Jan 10]. Available from: https://www.mdh.gov.br/biblioteca/consultorias/lgbt/violencia-Igbtfobicas-no-brasil-dados-da-violencia.

8. Secretaria de Direitos Humanos (Br). Relatório sobre violência homofóbica no Brasil: ano de 2013. 2016 [cited 2018 Jan 10]. Available from: http://www.direito.mppr.mp.br/arquivos/File/RelatorioViolenciaHomofobicaBR2013.pdf.

9. Oliveira DAG. O suicídio na comunidade LGBT no Brasil. Juíz de Fora (MG). [Monografia]. Universidade Federal de Juíz de Fora. 2018 [cited 2018 Jan 10]. Available from: http://www.ufjf.br/bach/files/2016/10/DAIANA-APARECIDA-GOMES-DEOLIVEIRA.pdf.

10. Oliveira DC, Polidoro M. Promotores e promotoras da saúde LGBT para profissionais no SUS. 2a ed. Porto Alegre (RS): UFRGS; 2018 [cited 2018 Jan 10]. Available from: https://www.lume.ufrgs.br/bitstream/handle/10183/189266/001082168.pdf?sequence=1\&isAllowed=y.

11. Ministério da Saúde (Br). Gays, Lésbicas, Bissexuais, Travestis e Transexuais. [Internet]. 2017 [cited 2018 Feb 15]; Available from: http://portalms.saude.gov.br/component/content/article/41380-gays-lesbicas-bissexuais-travestis-e-transexuais.

12. Ministério da Saúde (Br). Política Nacional de Saúde Integral de Lésbicas, Gays, Bissexuais, Travetis e Transexuais. 2013 [cited 2018 Feb 15]. Available from: http://bvsms.saude.gov.br/bvs/publicacoes/politicanacionalsaudelesbicasgays.pdf.

13. Silva IR, Leite JL, Lins MSB, Silva TP, Santos MJC. Orders and disorders: the complexity of adolescence and sexual health contributions to nursing. Rev. enferm. UERJ. 2016 [cited 2018 Feb 15]; 24(2):e14569. DOI: http://dx.doi.org/10.12957/reuerj.2016.14569.

14. Lima MDA, Souza AS, Dantas MF. Challenges the population of warranty rights Igbt Health System Single (SUS). Revista Interfaces. 2016 [cited 2018 Feb 15]; 3(11):119-125. Available from: https://interfaces.leaosampaio.edu.br/index.php/revistainterfaces/article/viewFile/315/224.

15. Wolff CS, Saldanha RA. Gênero, sexo, sexualidades: categorias do debate contemporâneo. Revista Retratos da Escola. 2015 [cited 2018 Feb 15]; 16(9):29-46. Available from: http://retratosdaescola.emnuvens.com.br/rde/article/view/482/595.

16. Rodrigues TS, Silva VR. Gender Trouble: A insuficiência da binaridade de gênero/sexo em Orlando: A biography de Virginia Woolf. Revista Traduzir-se. 2017 [cited 2018 Feb 19]; 3(5). Avaiable from: http://site.feuc.br/traduzirse/index.php/traduzirse/article/view/78/60.

17. Bolsoni-Silva AT, Loureiro SR. Validation of the social skills, behaviors and context assessment questionnaire for university students. Psic: Teor. e Pesq. 2016 [cited 2018 Feb 19]; 32(2):1-10. DOI: http://dx.doi.org/10.1590/0102-3772e322211.

18. Abreu PD, Araújo EC, Vasconcelos EMR, Moura JWS, Sousa JC, Santos CB. Transexual "womanhood" and the emergence of transfeminism: rhetorics of HIV/AIDS in the light of the queer theory. Texto \& contexto enferm. 2019 [cited 2019 Jan 11]; 28:e20180294. DOI: http://dx.doi.org/10.1590/1980-265X-TCE-2018-0294.

19. Tinney J, Dow B, Maude P, Purchase R, Whyte C, Barrett C. Mental health issues and discrimination among older LGBTI people. International Psychogeriatrics. 2015 [cited 2018 Sep 25]; 27(9):1411-16. DOI: http://dx.doi.org/10.1017/S1041610214002671. 
20. Albuquerque GA, Parente JS, Moreira FTLS. Violence as a violation of human rights of sexual minorities: impacts in health. Rev. Saúde. Com. 2017 [cited 2018 Sep 25]; 13(4):1034-43. DOI: https://dx.doi.org/10.22481/rsc.v13i4.475.

21. McConnell EA, Birkett MA, Mustanski B. Typologies of social support and associations with mental health outcomes among LGBT youth. LGBT Health. 2015 [cited 2018 Sep 25]; 2(1):55-61. DOI: http://dx.doi.org/10.1089/lgbt.2014.0051.

22. Macapagal K, Greene GJ, Rivera Z, Mustanski B. "The best is always yet to come": Relationship stages and processes among young LGBT couples. J. Fam. Pychol. 2015 [cited 2018 Sep 25]; 29(3):309-20. DOI: http://dx.doi.org/10.1037/fam0000094.

23. Birkett $M$, Newcomb ME, Mustanski B. Does It Get Better? A longitudinal analysis of psychological distress and victimization in lesbian, gay, bisexual, transgender, and questioning youth. Journal of Adolescent Health. 2015 [cited 2018 Sep 25]; 6(3):280-85. DOI: http://dx.doi.org/10.1016/j.jadohealth.2014.10.275.

24. Katz-Wise SL, Rosario M, Tsappis M. LGBT youth and family acceptance. Pediatr. Clin. North Am. 2016 [cited 2018 Sep 25]; 63(6):1011-25. DOI: http://dx.doi.org/10.1016/j.pcl.2016.07.005.

25. Mereish EH, Poteat VP. A relational model of sexual minority mental and physical health: the negative effects of shame on relationships, loneliness, and health. Journal of counseling psychology. 2015 [cited 2018 Sep 25]; 62(3):425-37. DOI: http://dx.doi.org/10.1037/cou0000088.

26. Xavier S, Nunes L, Basto ML. Emotional competence of the nurse: the significance of the construct. Pensar Enfermagem. Pensar Enfermagem - Revista. 2014 [cited 2018 Sep 25]; 18(2):3-19. Available from: http://pensarenfermagem.esel.pt/files/Artigo1_3_19.pdf.

27. Spindola T, Braga RMO, Marques SC, Formozo GA, Cecilio HPM, Oliveira DC. The self-protection against HIV for nursing professionals: study of social representations. Rev. enferm. UERJ. 2018 [cited 2018 Sep 25]; 26:e34277. DOI: http://dx.doi.org/10.12957/reuerj.2018.34277. 